\title{
ACCION ANTIMICROBIANA DE ALGUNAS PLANTAS DE USO MEDICINAL EN CHILE. II
}

Palabras Clave: Antimicrobiano, plantas Key words: Antimicrobial, plants

Waldo Lazo

Laboratorio de Botánica Criptogámica, Departamento de Ciencias Ecológicas Facultad de Ciencias, Universidad de Chile.

Héctor Bravo Laboratorio de Química Ecológica Departamento de Química Facultad de Ciencias, Universidad de Chile.

RESUMEN

El desarrollo de Staphylococcus aureus fue inhibido intensamente por extractos etanólicos de Gnaphalium vira-vira Mol., Muehlenbeckia hasiulata (J.E.Sm.) Johnst. $y$ Ribes punctautum R. et Pav, y sólo escasamente por sus extractos cloroförmicos. El desarrollo de Escherichia coli fue escasamente inhibido por el extracto etanólico de $M$. hastulata. El desarrollo de Candida albicans fue intensamente inhibido por el extracto etanólico de Solanum tomatillo Remy, escasamente inhibido por su extracto clorofórmico y los extractos etanólicos de M. hastulata, $R$. punctatum y Cestrum parqui L'Hérit.

\section{INTRODUCCION}

Lazo $(1987,1990)$ dio a conocer los resultados de sus investigaciones sobre la acción antimicrobiana de algunas plantas de uso medicinal en Chile. Silvay Bittneren Muñoz (1992), presentaron una revisión parcial de la literatura $\mathrm{s}$ bre la acción antibacteriana de plantas chilenas.

\section{MATERIALES Y METODOS}

Se sometió ramitas trozadas, completamente secas, de Muehlenbeckia hastulata (J.E.Sm.) Johnst, Ribes
SUMMARY

[Antimicrobian action of some plants of medical use in Chile.II I

The growth of Staphylococcus aureus was strongly inhibited by the ethanol extracts of Gnaphalium vira-vira Mol., Muehlenbeckia hastulata (J.E.Sm.) Johnst. and Ribes punctatum $R$. et Pav. and poorly inhibited by the chloroform extracts of these plants. The growth of Escherichia coli was poorly inhibited by the ethanol extract of M. hasiulata, The growth of Candides albicans was strongly inhibited by the ethanol extract of Solanum tomatillo Remy and poorly inhibited by the chloroform extracs of $S$. tomadillo and the ethanol extracts of $G$. Viravira, M. hastulata, R. punctatum ond Cestrum parqui L'Hérit.

punctatum R et Pav., Solanum tomatillo Remy, Cestrum parqui L'Hérit y flores secas de Gnaphalium visu-vira Mol., durante 24 horas, a extracción de sus principios antimicrobianos en etanol, cloroformo, acetato de tilo (30 gm de material en 100 a $150 \mathrm{ml}$ de solvente). Al cabo de ese tiempo se filtró cada exiracto, se lo colocó a evaporación al vacío a $35^{\circ} \mathrm{C}$ hasta reducirlo a un volumen de $30 \mathrm{ml}$. Luego se impregnó discos de papel âltro de $5 \mathrm{~mm}$ de diámetro en cada uno de los extractos, se dejó secar tales discos durante dos o más horas a la temperatura ambiente, y sólo cuando ellos estuvieron totalmente secos y sin rastro alguno del solvente usado, para conocer su actividad antimicótica se 
los depositó en la superficie de placas Petri, en las que previamente se había vertido una delgada capa de agar nutriente dextrosa inoculada con Canndida albicasss (cultivo de 24 horas),de modo que la concentración final en el medio fuera de $10^{4} \mathrm{UFC} / \mathrm{ml}$. Para conocer la acción antibacteriana, se procedió en forma parecida con cultivos de 20 horas de Staphylococcus aureus y Escherichia coli, inoculados respectivamente en distintas placas de Petri, de modo que la concentración final fuera de $10^{5} \mathrm{UFC} / \mathrm{ml}$. Para cultivar las bacterias se usó agar nutriente sin dextrosa. Se incubó a $35^{\circ} \mathrm{C}$ durante 24 horas las placas inoculadas con los microorganismos antes nombrados y en las que se había dispuesto los discos de papel filtro secos, impregnados dos o más horas antes, en extractos de diferentes plantas.

\section{RESULTADOS}

Los resultados de este ensayo se muestran en el
Cuadro 1.

Inhibieron marcadamente el desarrollo de $S$. asureus los extractos etanólicos de G. vira-vira, M. hastulata, y $\boldsymbol{R}$. punctatum. Los extractos clorofórmicos de las tres plantas antes nombradas inhibieron escasamente el desarrollo de S. aureus. El desarrollo de $E$. coli fue escasamente inhibido por el extracto etanólico de M. hastulata. El desarrollo de C. albicans fue intensamente inhibido por el extracto etanólico de $S$. tomatillo y escasamente inhibido por su extracto clorofórmico y los extractos etanólicos de $\boldsymbol{M}$. hastulata, $R$. punctatum y $C$. parqui. Los extractos en acetato de etilo de las plantas antes nombradas no evidenciaron actividad antimicrobiana alguna.

LaFoto 1 muestra la acción de extractos etanólicos de S. tomatillo y $G$. vira-vira sobre C. albicans.

La Foto 2 muestra la acción de extractos etanólicos de S. tomatillo y G. vira-vira sobre S. aureus.

CUADRO 1

Acción antimicrobiana de extractos de plantas estudiados in vitro

\begin{tabular}{|c|c|c|c|}
\hline & S. autreus & E. coli & C. albicans \\
\hline \multicolumn{4}{|c|}{ S. tomatillo (ramitas trozadas) } \\
\hline extr. etanólico & + & - & +++ \\
\hline extr. clorofórmico & - & - & + \\
\hline extr. acetato etilo & - & - & - \\
\hline \multicolumn{4}{|l|}{ G. vira-vira (flores) } \\
\hline extr. etanólico & $+4+$ & - & - \\
\hline extr. clorofórmico & + & - & - \\
\hline extr. acetato etilo & - & - & $=$ \\
\hline \multicolumn{4}{|c|}{ M. hastulata (ramitas trozadas) } \\
\hline extr. etanólico & +4 & + & + \\
\hline extr. clorofórmico & + & - & - \\
\hline extr. acetato etilo & + & - & - \\
\hline \multicolumn{4}{|c|}{ R. punctatum (ramitas trozadas) } \\
\hline extr. etanólico & $++t$ & - & + \\
\hline extr. clorofórmico & + & - & - \\
\hline extr. acetato etilo & - & $=$ & - \\
\hline \multicolumn{4}{|c|}{ C. parqui (ramitas trozadas) } \\
\hline extr. etanólico & - & - & + \\
\hline extr. clorofórmico & - & - & - \\
\hline extr. acetato etilo & - & - & - \\
\hline
\end{tabular}


Foto 1. Acción sobre C. albicans tras 24 horas de incubación a $35^{\circ} \mathrm{C}$ de extractos etanólicos de: A: S. tomatillo. B: G. vira-vira.

Foto 2. Accion sobre $S$. aureus tras 24 horas de incubación a $35^{\circ} \mathrm{C}$ de extractos etanólicos de: A: S. tomatillo. B: G. vira-vira. (Fotos Rubén Peña)

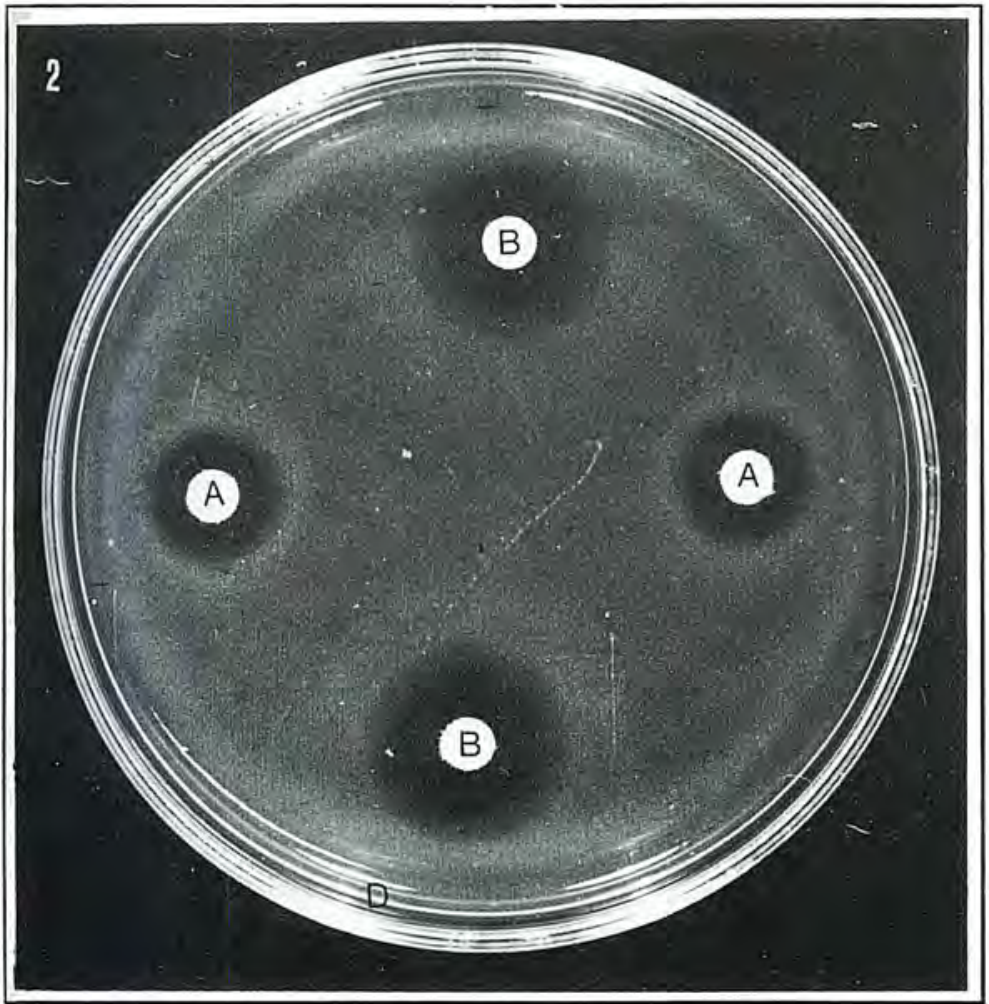

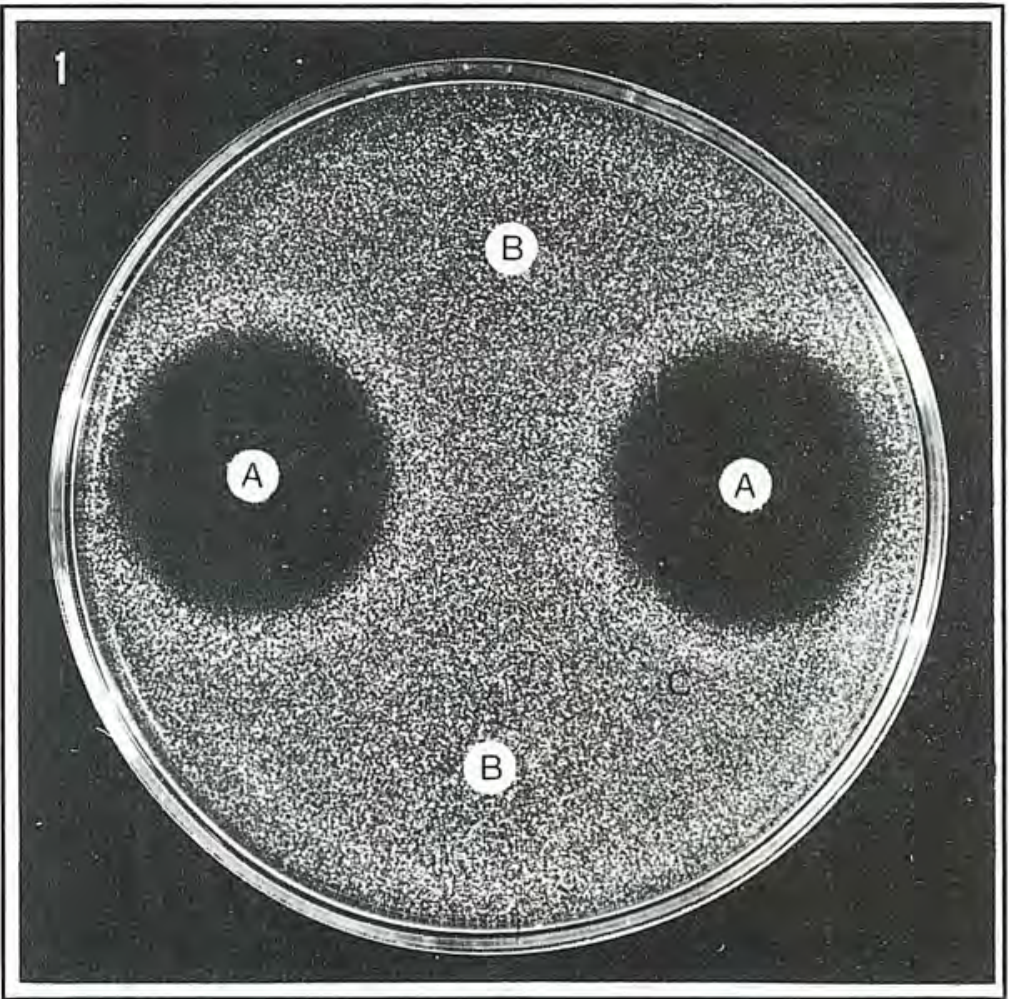

\section{REFERENCIAS}

Lazo, W. (1987). Acción antimicótica de algunas plantas chilenas. Bol. Micol. 3 : 191-193

Lazo, W. (1990). Acción antimicrobiana de algunas plantas de uso medicinal en Chile. I. Bol. Micol 5 $(1-2): 25-28$.

Muñoz, O. (1992). Química de la Flora de Chile. D.T. I, Universidad de Chile. 